\title{
VALUASI SUMBERDAYA AIR (STUDI KASUS KAWASAN MATA AIR TATANEYAN DI KELURAHAN KINILOW I, KECAMATAN TOMOHON UTARA, KOTA TOMOHON)
}

\author{
Rolla A.C. Lopis \\ O. Esry. H. Laoh \\ Mex L. Sondakh
}

\begin{abstract}
This study aims to determine how how big the valuations of water in the spring Tataneyan located in the Village Kinilow I, District of North Tomohon, Tomohon, by using the concept of economic valuation to calculate the value of the utilization of water resources directly or indirectly. This study was conducted from October to December 2016, using primary and secondary data with sampling technique simple random sampling method and the respondents as many as 30 people. Analysis of the data used is quantitative analysis to identify the value of the value of benefits in the area of water resources in the waters Tataneyan value direct use for domestic households and public bath are also value the presence of fish breeding and agricultural irrigation water spinach. The results showed that the area of the springs Tataneyan have a total economic benefit value of Rp. 1.586.715.372/year. By calculating the average value of the obtained surplus WTP consumers showed the overall consumer receives more benefits than the actual price that is able to pay in exploiting springs Tataneyan. The total value of economic benefits can be used as a reference for local communities in the utilization and management of water in the spring Tataneyan.
\end{abstract}

Keywords : Economic Valuation, Water Resources, WTP( Willingness to pay), Kinilow, Tomohon

\begin{abstract}
ABSTRAK
Penelitian ini bertujuan untuk mengetahui seberapa besar valuasi sumberdaya air di kawasan mata air Tataneyan yang berada di Kelurahan Kinilow 1, Kecamatan Tomohon Utara, Kota Tomohon dengan konsep valuasi ekonomi untuk menghitung nilai pemanfaatan sumberdaya air secara langsung maupun tidak langsung. Penelitian ini dilaksanakan pada bulan Oktober sampai Desember 2016, menggunakan data primer dan sekunder dengan teknik pengambilan sampel metode simple random sampling dan responden sebanyak 30 orang. Analisis data yang digunakan adalah analisis kuantitatif untuk mengindentifikasi nilai manfaat di dalam Sumber Daya Air di Kawasan Mata Air Tataneyan yaitu nilai penggunaan langsung untuk kebutuhan domestik rumah tangga dan permandian umum juga nilai keberadaan untuk pembibitan ikan dan irigasi pertanian kangkung. Hasil penelitian menunjukkan bahwa kawasan mata air Tataneyan mempunyai nilai manfaat ekonomi total sebesar Rp. 1.586.715.372/tahun. Dengan menghitung nilai rata-rata WTP maka diperoleh surplus konsumen yang menunjukkan keseluruhan konsumen menerima keuntungan lebih dari harga sebenarnya yang mampu mereka bayar dalam memanfaatkan mata air Tataneyan. Nilai manfaat ekonomi total ini dapat dijadikan acuan bagi masyarakat setempat dalam pemanfaatan dan pengelolaan air di kawasan mata air Tataneyan.
\end{abstract}

Kata Kunci : valuasi ekonomi, sumberdaya air, WTP (willingness to pay), Kinilow, Tomohon 


\section{PENDAHULUAN}

Air memegang peranan penting di dalam kehidupan manusia dan makhluk hidup lainnya, kebutuhan akan air untuk keberlangsungan hidup manusia sangat tinggi. Hal ini terlihat dari pemanfaatan air untuk pemenuhan kebutuhan belum dapat digantikan dengan barang lainnya. Air memberikan manfaat bagi kehidupan manusia baik secara langsung maupun tidak langsung dalam hal ini digunakan untuk keperluan domestik rumah tangga seperti mandi, minum, dan masak juga dapat digunakan untuk irigasi, pembangkit listrik, peternakan dan perikanan. Ketersediaan air mempengaruhi banyak sektor dalam kehidupan manusia dalam hal ini tidak hanya jumlah air yang tersedia (kuantitas) namun kualitas serta distribusi air yang ada disuatu wilayah tertentu menjadi faktor penentu dalam kesejahteraan hidup manusia (Putri, 2013). Beberapa kajian menunjukan bahwa banyak negara berkembang diprediksikan mengalami kelangkaan air tanpa upaya yang serius, dalam hal ini kelangkaan air bersih, ketahanan pangan melemah, dan kemiskinan meluas (Gleick, 2000).

Air menjadi sesuatu yang dapat dinilai karena dapat memberikan manfaat dan kegunaan bagi individu maupun masyarakat, nilai yang dimiliki air dapat berupa nilai ekonomi yaitu air dapat secara langsung memberikan manfaat berupa pendapatan (Suparmoko dalam Putri, 2013). Kebutuhan air di seluruh sektor perekonomian terus meningkat seiring dengan perkembangan ekonomi dan pertumbuhan penduduk bahkan banyak yang tercemar bermacam-macam limbah dari hasil aktivitas rumah tangga, limbah pertanian, peternakan dan industri. Manfaat air terdiri dari manfaat nyata yang terukur (tangible) serta manfaat yang tidak terukur (intangible). Harnanto (2007), menyatakan bahwa air harus digunakan sebagai barang ekonomis dan penggunaannya harus diatur agar tercapai kesejahteraan masyarakat yang optimal.

Kota Tomohon memiliki sumber daya air berupa air permukaan dan tanah yang potensial. Hal tersebut nampak dari beberapa sungai yang berukuran cukup besar dan mata air yang merupakan sumber potensial bagi penyedia kebutuhan air baku penduduk, salah satunya berada di Kelurahan Kinilow 1 dengan luas wilayah $\pm 450 \mathrm{Ha} / \mathrm{m}^{2}$ dan jumlah penduduk 2.642 jiwa memiliki sumber mata air Tataneyan yang dimanfaatkan untuk kebutuhan domestik rumah tangga sekitar kawasan mata air, dijadikan tempat permandian umum untuk warga setempat, pembibitan ikan serta irigasi seluas $\pm 10 \mathrm{Ha}$. Untuk kebutuhan warga setempat sampai saat ini belum dipungut biaya apapun padahal merupakan aset yang perlu dikelola demi kelestarian fungsi dan keberlangsungan mata air Tataneyan.

\section{Rumusan Masalah}

Berapa besar valuasi sumberdaya air kawasan mata air Tataneyan di Kelurahan Kinilow 1, Kecamatan Tomohon Utara, Kota Tomohon.

\section{Tujuan Penelitian}

Menghitung valuasi sumberdaya air kawasan mata air Tataneyan di Kelurahan Kinilow 1, Kecamatan Tomohon Utara, Kota Tomohon.

\section{Manfaat Penelitian}

Penelitian ini diharapkan memberikan informasi bagi masyarakat dan instansi terkait sehingga alokasi penggunaan air di Kawasan Mata Air Tataneyan akan lebih optimal dan semakin dipertahankan.

\section{METODOLOGI PENELITIAN}

\section{Waktu dan Tempat Penelitian}

Penelitian ini dilaksanakan selama 3 (tiga) bulan dari bulan Oktober hingga bulan Desember 2016. Tempat penelitian dilaksanakan di Kelurahan Kinilow 1, Kecamatan Tomohon Utara, Kota Tomohon.

\section{Metode Pengumpulan Data}

Penelitian ini menggunakan data primer dan sekunder. Data primer bersumber dari wawancara langsung dengan responden. Wawancara berdasarkan daftar pertanyaan yang telah disiapkan atau menggunakan kuesioner bagi responden yang memanfaatkan air di kawasan mata air Tataneyan seperti data pemanfaatan air untuk kebutuhan domestik rumah tangga, pemanfaatan air untuk kebutuhan mandi/ membersihkan diri (permandian umum), budidaya ikan, dan pemanfaatan air untuk irigasi. Data sekunder yang bersumber dari instansi yang terkait dengan penelitian ini. 


\section{Metode Pengambilan Sampel}

Untuk pengambilan sampel akan menggunakan metode pengambilan Simple Random Sampling (sederhana) karena pengambilan sampel data atau responden dilakukan secara acak. Masyarakat yang dijadikan sampel atau responden adalah mereka yang memanfaatkan mata air Tataneyan baik untuk kebutuhan domestik rumah tangga, kebutuhan mandi/membersihkan diri, (permandian umum), pemanfaatan air irigasi (pertanian kangkung) dan pembibitan ikan. Responden diambil sebanyak 30 orang.

\section{Konsep Pengukuran Variabel}

Adapun variabel yang akan di ukur dalam penelitian ini adalah :

1. Nilai Penggunaan Langsung yaitu nilai yang dihasilkan dari pemanfaatan secara langsung mata air Tataneyan :

- Penggunaan air untuk keperluan domestik rumah tangga dari masyarakat sekitar kawasan mata air Tataneyan $=\mathrm{Rp} /$ tahun

- Kebutuhan membersihkan diri/mandi (permandian umum) dari masyarakat sekitar kawasan mata air Tataneyan :

Kesediaan membayar masyarakat (Willingness to Pay) $=\mathrm{Rp} /$ tahun

2. Nilai keberadaan yaitu nilai yang diperoleh dari pemanfaatan mata air Tataneyan untuk pembibitan ikan dan air irigasi.

- Pembibitan ikan = Rp / tahun

- Pemanfaatan air irigasi $=\mathrm{Rp} /$ tahun

\section{Metode Analisis Data}

Analisis data yang akan digunakan dalam penelitian ini adalah analisis kuantitatif untuk data data yang menunjukan kuantitas atau jumlah dalam bentuk angka. Perhitungan nilai ekonomi total (Total Economic Value) didahului dengan mengidentifikasi nilai nilai yang terkandung di dalam sumber daya air di kawasan mata air Tataneyan sebagai berikut :

\section{Nilai Penggunaan Langsung}

Nilai penggunaan langsung sumber daya air di kawasan mata air Tataneyan digunakan untuk sumber bahan baku atau kebutuhan domestik rumah tangga, dan sebagai tempat permandian umum.

\section{a. Kebutuhan Domestik Rumah Tangga}

Pendekatan yang digunakan untuk kebutuhan domestik rumah tangga seperti kebutuhan minum, memasak, mencuci dan kakus adalah pendekatan teknik pasar yaitu dengan cara sebagai berikut :

Dimana :

$$
\text { NART }=\text { RTPA } \times \text { JA } \times \text { KP } \times \text { HAS }
$$

NART : Nilai ekonomi pemanfaatan air rumah tangga (Rp/Thn)

RTPA : Jumlah rumah tangga pemanfaat air (RT/KK)

JA : Rata-rata jumlah anggota keluarga (Org/Jiwa)

KP : Komsumsi rata-rata air (L/Org/Thn)

HAS : Harga setara Aquwar (Rp/L)

\section{b. Tempat Permandian Umum (Metode Willingness to Pay)}

Untuk menilai sumber daya air di kawasan mata air Tataneyan yang digunakan sebagai tempat permandian umum maka digunakan metode kesediaan untuk membayar (willingness to pay). Parameter dapat digolongkan ke dalam beberapa aspek diantaranya : jarak responden ke mata air, jumlah pengguna air, kualitas air, dan nilai Willingness to Pay (WTP) yang ditawarkan responden.

\section{c. Analisis Nilai WTP Responden terhadap Pembayaran Jasa Lingkungan}

1. Menghitung Dugaan Nilai Rata-Rata WTP (Calculating Average WTP)

Willingness to pay (WTPi) dapat diduga dengan rumus :

Ket:

$$
\sum \mathrm{WTP}=\sum_{\mathrm{i}=1}^{\mathrm{n}} \mathrm{W}_{\mathrm{i}} \text {. Pfi }
$$

$$
\begin{array}{ll}
\sum_{\mathrm{WTP}} & =\text { Dugaan Rataan WTP } \\
\mathrm{W}_{\mathrm{i}} & =\text { Batas bawah kelas WTP } \\
\mathrm{Pfi} & =\text { Frekuensi relatif kelas tertentu } \\
\mathrm{n} & =\text { Jumlah Kelas } \\
\mathrm{i} & =\text { Kelas ke }-\mathrm{i}
\end{array}
$$

\section{Menghitung Surplus Konsumen}

Berdasarkan dugaan kurva penawaran WTP dapat dihitung surplus konsumen yang akan diperoleh masyarakat. Surplus konsumen adalah surplus atau kelebihan yang diterima responden karena nilai WTP yang diinginkan lebih tinggi daripada nilai WTP rata-ratanya. Perhitungan surplus konsumen dapat didasarkan pada rumus Merryna dalam Nasution (2015). 


$$
\mathrm{SK}=\sum\left(\mathrm{WTP}_{\mathrm{i}}-\mathrm{P}\right) \text { dimana } \mathrm{WTP}>\mathrm{P}
$$

Ket :

$$
\begin{array}{ll}
\text { SK } & =\text { Surplus Konsumen } \\
\text { WTP }_{\mathrm{i}} & =\text { WTP responden ke- } \mathrm{i} \\
\mathrm{P} & =\mathrm{WTP} \text { rata-rata }
\end{array}
$$

\section{Menjumlahkan Data (Agregating Data /} TWTP)

Penjumlahan data merupakan proses dimana nilai tengah penawaran dikonversikan terhadap total populasi yang dimaksud. Setelah menduga nilai kerelaan membayar maka dapat diduga nilai WTP. berikut :

Adapun formulasi adalah sebagai

$$
\mathrm{TWP}=\sum_{\mathrm{i}=\mathrm{I}}^{0} \mathrm{AWP}_{\mathrm{i}} \frac{\mathrm{ni}}{\mathrm{N}} \mathrm{X} \text { Populasi }
$$

Ket :

TWP = kesediaan membayar total

$\mathrm{AWP}_{\mathrm{i}}=$ kesediaan membayar rata-rata

ni = banyaknya responden yang bersedia membayar AWP i

$\mathrm{N}$ = banyaknya orang yang diwawancarai sebagai sampel.

\section{Nilai Keberadaan}

Nilai keberadaan sumber daya air di kawasan mata air Tataneyan terdiri atas pemanfaatan air untuk lahan pertanian kangkung dan pembibitan ikan. Dengan menghitung jumlah keuntungan petani kangkung dan pembibitan ikan dikali luas lahan, sebagai total keberadaan sumber daya air kawasan mata air Tataneyan.

\section{Nilai Ekonomi Total}

Dalam hal ini menjumlahkan semua nilai-nilai yang terkandung di dalam sumber daya air kawasan mata air Tataneyan, yaitu :

$$
\mathrm{NET}=(\mathrm{NPL}+\mathrm{NK})
$$

Ket :

NET = Nilai Ekonomi Total

NPL = Nilai Penggunaan Langsung

NK $=$ Nilai Keberadaan

\section{HASIL DAN PEMBAHASAN}

\section{Deskripsi Lokasi Penelitian}

Kinilow satu merupakan salah satu Kelurahan yang berada di Tomohon Utara, Kota Tomohon, Provinsi Sulawesi Utara. Saat ini Kinilow terdiri atas dua Kelurahan yaitu Kinilow dan Kinilow satu. Kelurahan Kinilow 1 dahulunya Desa Kinilow 1 dimekarkan dari Desa Kinilow pada tanggal 20 Oktober 2004 berdasarkan Keputusan Walikota Tomohon No 05 Tahun 2004. Berdasarkan keputusan Walikota Tomohon No 06 Tahun 2004, berubah status dari Desa menjadi Kelurahan. Kelurahan Kinilow satu mempunyai 11 lingkungan dengan jumlah penduduk 2.642 jiwa, jumlah Kepala Keluarga $764 \mathrm{KK}$ dengan luas wilayah kurang lebih $450 \mathrm{Ha} / \mathrm{m}^{2}$, memiliki sumber mata air Tataneyan yang terletak di lingkungan 3 dan dimanfaatkan oleh masyarakat dengan batas batas wilayah Kelurahan Kinilow satu sebagai berikut :

Sebelah Utara : Kelurahan Kinilow

Sebelah Selatan: Kelurahan Kakaskasen I

Sebelah Timur : Hutan

Sebelah Barat : Hutan

Sebelum dihitung nilai ekonomi air, maka terlebih dahulu dihitung komponen komponen yang membentuk nilai-nilai tersebut, yaitu :

\section{Nilai Penggunaan Langsung}

Air yang dimaksud dalam penelitian ini adalah air yang bersumber dari mata air Tataneyan, Kelurahan Kinilow 1, Kecamatan Tomohon Utara, Kota Tomohon. Dimanfaatkan untuk kebutuhan domestik rumah tangga seperti memasak, minum, mencuci, mandi dan sebagai tempat permandian umum masyarakat di sekitar kawasan mata air Tataneyan.

\section{Kebutuhan Domestik Rumah Tangga}

Harga dasar air yang digunakan adalah standar Air Aqawar (Aqua Warembungan) sebagai pemasok air bersih atau air minum isi ulang, dengan menggunakan pendekatan teknik pasar, dalam kapasitas 7500 L harganya Rp.300.000 jadi 1 liter perhitungannya Rp.40,Dapat dilihat pada Tabel 1. 
Tabel 1. Nilai Pemanfaatan Air Untuk Kebutuhan Domestik Rumah Tangga

\begin{tabular}{cccccccr}
\hline No & Lingk & $\begin{array}{c}\text { Populasi } \\
(\mathbf{K K})\end{array}$ & $\begin{array}{c}\text { RTPA } \\
(\mathbf{R T})\end{array}$ & JA (org) & $\begin{array}{c}\text { KP } \\
(\mathbf{L} / \mathbf{O r g} / \mathbf{T h n})\end{array}$ & $\begin{array}{c}\text { HAS } \\
(\mathbf{R P / L})\end{array}$ & $\begin{array}{c}\text { NART } \\
(\mathbf{R p / T h n})\end{array}$ \\
\hline 1 & 1 & 82 & 48 & 3 & 21.600 & 40 & 124.416 .000 \\
2 & 2 & 68 & 32 & 4 & 21.600 & 40 & 110.592 .000 \\
3 & 3 & 61 & 61 & 4 & 21.600 & 40 & 210.816 .000 \\
4 & 4 & 47 & - & - & - & - & - \\
5 & 5 & 80 & - & - & - & - & - \\
6 & 6 & 76 & - & - & - & - & - \\
7 & 7 & 68 & 44 & 2 & 21.600 & 40 & 76.032 .000 \\
8 & 8 & 75 & - & & & & 148.608 .000 \\
9 & 9 & 83 & 43 & 4 & 21.600 & 40 & - \\
10 & 10 & 52 & - & - & - & - & 120.960 .000 \\
11 & 11 & 72 & 35 & 4 & 21.600 & 40 & $\mathbf{7 9 1 . 4 2 4 . 0 0 0}$ \\
\hline
\end{tabular}

Sumber : Data Olahan

Dengan demikian terdapat 6 lingkungan di Kelurahan Kinilow Satu yang memanfaatkan air di kawasan mata air Tataneyan, pengguna berjumlah 263 Kepala Keluarga, rata-rata penggunaan air $60 \mathrm{~L} / \mathrm{Org} / \mathrm{Hari}$, maka nilai ekonomi air untuk kebutuhan domestik rumah tangga di kawasan mata air Tataneyan adalah sebesar Rp. 791.424.000/Tahun.

\section{Tempat Permandian Umum Metode (Willingness to Pay)}

Sumberdaya air di kawasan mata air Tataneyan juga dimanfaatkan oleh masyarakat setempat dan sekitarnya sebagai tempat permandian umum yang dihitung dengan metode Willingness to Pay (WTP). Masyarakat yang dijadikan sampel adalah 30 responden, parameter dari penelitian ini dapat digolongkan ke dalam beberapa aspek diantaranya adalah : jarak responden ke mata air, jumlah pengguna air, kualitas air dan nilai Willingness to Pay (WTP) yang ditawarkan responden.

\section{Jarak Rumah ke Sumber Air}

Jarak ke mata air ini merupakan jarak yang ditempuh responden menuju sumber air. Pengelompokan data ini menggunakan skala interval yaitu aturan strugess dalam Nasution (2015). Rekapitulasi datanya dapat dilihat pada Tabel 2.

\section{Jumlah Pengguna Air}

Jumlah pengguna air merupakan jumlah anggota keluarga dari masing-masing responden yang diwawancarai yang turut memanfaatkan mata air. Rekapitulasi datanya dapat dilihat pada Tabel 3.

\section{Kualitas Air}

Kualitas air ini dapat dinilai oleh responden sendiri, memberikan penilaian mata air sesuai dengan yang sebenarnya berdasarkan kriteria yang telah ditentukan pada kuesioner. Rekapitulasi datanya dapat dilihat pada Tabel 4.

\section{Nilai Willingness to Pay (WTP) yang Ditawarkan Nilai WTP adalah nilai rupiah yang ditawarkan oleh masing-masing responden yang telah dimanfaatkan bersama oleh masyarakat. Rekapitulasi datanya dapat dilihat pada Tabel 5.}

Tabel 2. Rekapitulasi Data Responden Berdasarkan Jarak Rumah ke Sumber Air

\begin{tabular}{cccc}
\hline No & $\begin{array}{c}\text { Jarak } \\
\text { (Meter) }\end{array}$ & $\begin{array}{c}\text { Jumlah } \\
(\text { KK) }\end{array}$ & $\begin{array}{c}\text { Persentase } \\
(\boldsymbol{\%})\end{array}$ \\
\hline 1 & $90-210$ & 8 & 26,67 \\
2 & $211-330$ & 2 & 6,67 \\
3 & $331-450$ & 6 & 20,00 \\
4 & $451-570$ & 0 & 0,00 \\
5 & $571-690$ & 4 & 13,33 \\
6 & $691-810$ & 10 & 33,33 \\
\hline & JUMLAH & $\mathbf{3 0}$ & $\mathbf{1 0 0}$ \\
\hline
\end{tabular}

Sumber : Data Olahan dari kuesioner 
Tabel 3. Rekapitulasi Data Responden Berdasarkan Jumlah Pengguna Air

\begin{tabular}{cccc}
\hline No & $\begin{array}{c}\text { Jumlah Pengguna Air } \\
\text { (Orang) }\end{array}$ & $\begin{array}{c}\text { Jumlah } \\
(\text { KK) }\end{array}$ & $\begin{array}{c}\text { Persentase } \\
(\mathbf{\%})\end{array}$ \\
\hline 1 & $1-2$ & 6 & 20,00 \\
2 & $3-4$ & 19 & 63,33 \\
3 & $5-6$ & 4 & 13,33 \\
4 & $7-8$ & 1 & 3,33 \\
\hline & JUMLAH & $\mathbf{3 0}$ & $\mathbf{1 0 0}$ \\
\hline
\end{tabular}

Sumber : Data Olahan Kuesioner

Tabel 4. Rekapitulasi Data Responden Berdasarkan Penilaian Kualitas Air

\begin{tabular}{cccc}
\hline No & Kualitas Air & $\begin{array}{c}\text { Jumlah } \\
(\text { KK) }\end{array}$ & $\begin{array}{c}\text { Persentase } \\
(\boldsymbol{\%})\end{array}$ \\
\hline 1 & Jernih & 9 & 30,00 \\
2 & Biasa & 21 & 70,00 \\
3 & Kotor & 0 & 0,00 \\
\hline & JUMLAH & $\mathbf{3 0}$ & $\mathbf{1 0 0}$ \\
\hline
\end{tabular}

Sumber : Data Olahan Kuesioner

Tabel 5. Rekapitulasi Data Responden Berdasarkan Nilai WTP

\begin{tabular}{rccc}
\hline No & Nilai Yang Ditawarkan (Rp/Bln) & Jumlah $($ KK) & Persentase (\%) \\
\hline 1 & 0 & 2 & 6,67 \\
2 & 5.000 & 5 & 16,67 \\
3 & 10.000 & 5 & 16,67 \\
4 & 20.000 & 7 & 23,33 \\
5 & 25.000 & 6 & 20,00 \\
6 & 50.000 & 5 & 16,67 \\
\hline & JUMLAH & $\mathbf{3 0}$ & $\mathbf{1 0 0}$ \\
\hline
\end{tabular}

Sumber : Data Olahan Kuesioner

Analisis Willingness to Pay (WTP) Masyarakat Terhadap Pembayaran Jasa Lingkungan Mata Air Tataneyan

\section{Menghitung Dugaan Nilai Rata-rata WTP/EWTP}

Data pada Tabel 6, menunjukan dugaan nilai WTP (EWTP) responden yang dihitung berdasarkan data distribusi WTP responden dengan menggunakan Rumus persamaan (1). Pengelompokan data ini menggunakan skala interval yaitu aturan strugess dalam Nasution (2015). Dengan demikian dapat diperoleh nilai rata-rata WTP (EWTP) sebesar Rp. 15.792,39/KK/Bln, yang merupakan tingkat kerelaan membayar masyarakat di sekitar kawasan mata air Tataneyan.

Berdasarkan nilai rata-rata WTP (EWTP) maka diperoleh total (agregat) surplus konsumen responden terhadap pembayaran jasa lingkungan kawasan mata air Tataneyan berdasarkan rumus persamaan (2) adalah sebesar Rp.144.145,98. Ini berarti keseluruhan konsumen menerima keuntungan lebih dari harga sebenarnya yang mampu mereka bayar dalam memanfaatkan air pada mata air Tataneyan.

\section{Memperkirakan Kurva WTP (Estimating Bid Curve)}

Kurva WTP responden berdasarkan nilai WTP responden terhadap jumlah Responden yang memilih nilai WTP tersebut. Berdasarkan Gambar 1, maka dapat dijelaskan kurva permintaan WTP terhadap pembayaran jasa lingkungan di kawasan mata air Tataneyan berada pada tingkatan harga Rp.20.000/bulan.

\section{WTP Agregat atau Total WTP (TWTP)}

Nilai total (TWTP) responden dihitung berdasarkan data distribusi WTP responden dengan rumus persamaan (3). Pengelompokan data ini menggunakan skala interval yaitu aturan strugess dalam Nasution (2015). Berdasarkan hasil perhitungan diperoleh nilai total WTP (willingness to pay) adalah sebesar Rp. 52.524.281/bulan atau Rp.630.291.372/ tahun yang merupakan tingkat kesediaan membayar total masyarakat di kawasan mata air Tataneyan. Hasil perhitungan inilah yang dijadikan nilai ekonomi pembayaran jasa lingkungan masyarakat dalam pemanfaatan air di kawasan mata air Tataneyan yang dijadikan tempat permandian umum. Dapat dilihat pada Tabel 7. 
Tabel 6. Distribusi WTP/EWTP Responden Masyarakat Pengguna Mata Air Tataneyan

\begin{tabular}{ccccr}
\hline No & Kelas fi & $\begin{array}{c}\text { Frekuensi } \\
\text { Responden } \\
\text { (orang) }\end{array}$ & $\begin{array}{c}\text { Frekuensi relatif } \\
\text { (pfi) }\end{array}$ & Wi \\
\hline 1 & $0-8.400$ & 7 & 0,23 & 0,00 \\
2 & $8.401-16.800$ & 5 & 0,17 & $1.428,09$ \\
3 & $16.801-25.200$ & 13 & 0,43 & $7.224,22$ \\
4 & $25.201-33.600$ & 0 & 0,00 & 0,00 \\
5 & $33.601-42.000$ & 0 & 0,00 & 0,00 \\
6 & $42.001-50.400$ & 5 & 0,17 & $7.140,09$ \\
\hline & Total & $\mathbf{3 0}$ & $\mathbf{1 , 0 0}$ & $\mathbf{1 5 . 7 9 2 , 3 9}$ \\
\hline
\end{tabular}

Sumber : Data Olahan

Tabel 7 . Total WTP Responden Masyarakat terhadap Pembayaran Jasa Lingkungan Mata Air Tataneyan.

\begin{tabular}{|c|c|c|c|c|c|}
\hline No & $\begin{array}{c}\text { Kesediaan } \\
\text { membayar } \\
(\mathrm{Rp} / \mathrm{KK} / \mathrm{Bln})\end{array}$ & Rata-rata & $\begin{array}{l}\text { Jumlah } \\
\text { Responden } \\
\text { (org) }\end{array}$ & $\begin{array}{c}\text { Persentase } \\
(\%)\end{array}$ & Nilai (Rp/Bln) \\
\hline 1 & $0-8.400$ & $4.200,5$ & 7 & 23,33 & $2.589 .468,23$ \\
\hline 2 & $8.401-16.800$ & $12.600,5$ & 5 & 16,67 & $5.548 .420,17$ \\
\hline 3 & $16.801-25.200$ & $21.000,5$ & 13 & 43,33 & $24.042 .772,43$ \\
\hline 4 & $25.201-33.600$ & $29.400,5$ & 0 & 0,00 & 0,00 \\
\hline 5 & $33.601-42.000$ & $37.800,5$ & 0 & 0,00 & 0,00 \\
\hline 6 & $42.001-50.400$ & $46.200,5$ & 5 & 16,67 & $20.343 .620,17$ \\
\hline \multirow{2}{*}{\multicolumn{2}{|c|}{$\begin{array}{l}\text { Jumlah } \\
\text { Jumlah Total } \\
\text { (Rp/Tahun) }\end{array}$}} & & 30 & 100 & $52.524 .281,00$ \\
\hline & & & & & 630.291.372 \\
\hline
\end{tabular}

Sumber : Data Olahan

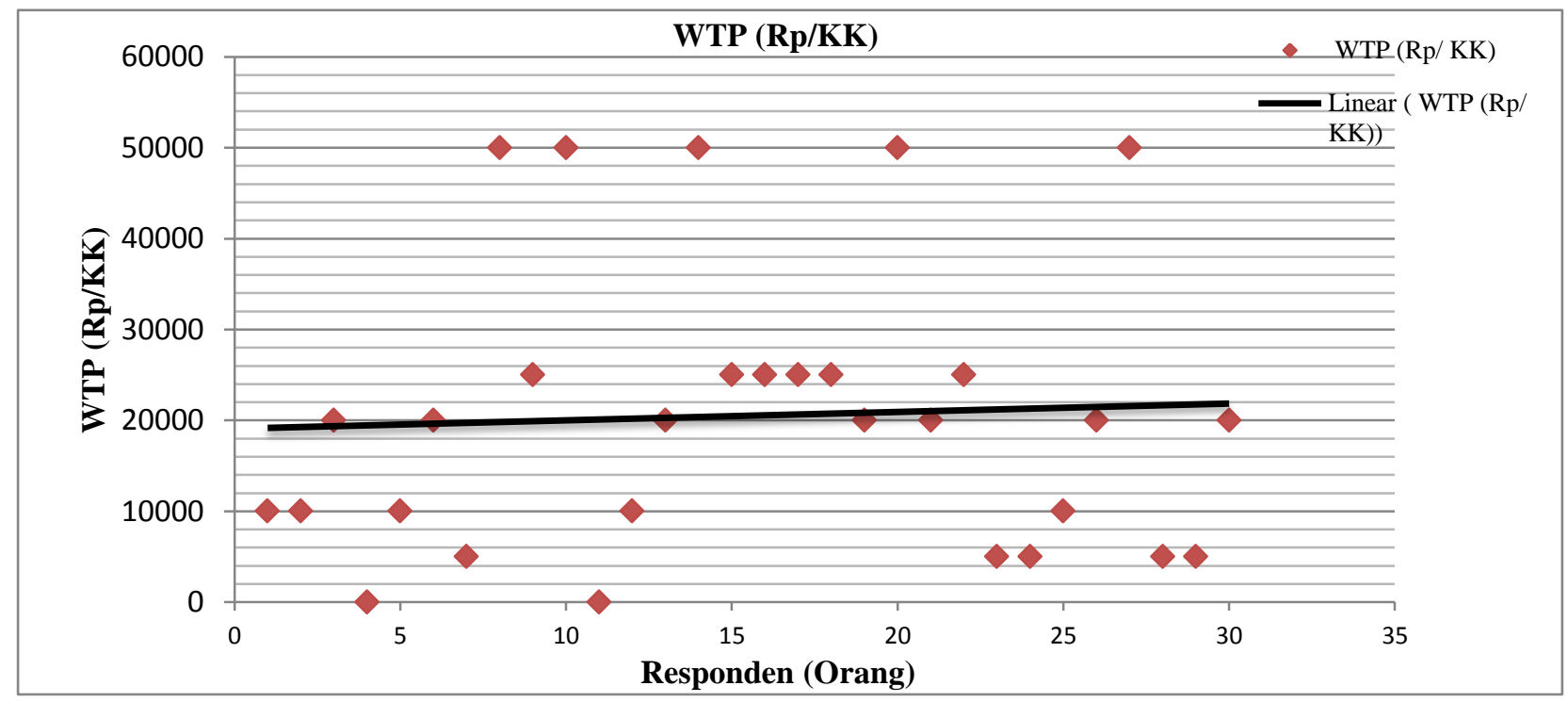

Gambar 1. Kurva Penawaran WTP Terhadap Pembayaran Jasa Lingkungan 


\section{Nilai Keberadaan Pemanfaatan Air}

Nilai keberadaan yang dimaksud dalam penelitian ini adalah pemanfaatan air untuk pembibitan ikan dan irigasi pertanian kangkung yang berada di kawasan mata air Tataneyan.

Berdasarkan Tabel 8, nilai ekonomi keberadaan pemanfaatan air untuk pembibitan ikan di kawasan mata air Tataneyan didapat dari 3 jenis ikan yaitu: ikan nila, ikan mas dan ikan koi dengan luas lahan 0,4 ha, ukuran rata-rata $5,8 \mathrm{~cm}$ dan umur panen rata-rata 2,5 bulan atau sekitar 45 kali panen dalam setahun. Maka sesuai perhitungan nilai ekonomi pemanfaatan air untuk pembibitan ikan adalah sebesar Rp. 105.000.000/Tahun.

Untuk irigasi dalam hal ini pertanian kangkung dalam setahun petani memanen kangkung sebanyak 12 kali dengan rata-rata luas lahan irigasi 0,4 ha dan volume rata-rata panen/bulan sebesar 5000 ikat, satu ikatnya dihargai Rp.1000 dengan total keseluruhan luas lahan irigasi di Kawasan Mata Air Tataneyan adalah 10 ha. Maka perhitungan pemanfaatan air untuk lahan irigasi pertanian kangkung adalah sebesar Rp.60.000.000/tahun.

\section{Nilai Ekonomi Total Pemanfaatan Air}

Untuk menilai total pemanfaatan air di kawasan mata air Tataneyan maka dihitung dengan konsep total nilai ekonomi ( total economic value), yaitu menjumlahkan semua nilai-nilai manfaat. Maka dugaan nilai ekonomi total pemanfaatan air di kawasan mata air Tataneyan adalah sebesar Rp.1.586.715.372/ tahun. Nilai manfaat langsung untukkebutuhan domestik rumah tangga memberikan kontribusi yang paling tinggi yaitu Rp. 791.424.000/tahun kemudian nilai manfaat langsung untuk permandian umum sebesar Rp. 630.291.372/Tahun dan nilai manfaat keberadaan untuk pembibitan ikan sebesar Rp.105.000.000/tahun

Sedangkan yang paling rendah nilai manfaat keberadaan untuk irigasi pertanian kangkung sebesar Rp.60.000.000/tahun (Tabel 9)

Dengan diperolehnya nilai manfaat ekonomi total dari pemanfaatan sumberdaya air kawasan mata air Tataneyan di Kelurahan Kinilow 1, Kecamatan Tomohon Utara, Kota Tomohon, diharapkan dapat dijadikan acuan bagi masyarakat dalam pengelolaan dan pemanfaatan mata air Tataneyan. Hasil penilaian ekonomi menunjukkan bahwa kawasan mata air Tataneyan mempunyai nilai manfaat yang cukup besar yang dapat menunjang kehidupan bahkan perekonomian masyarakat di sekitar kawasan mata air Tataneyan. Dengan demikian masyarakat diharapkan agar dapat saling menopang dan bekerjasama untuk tetap menjaga dan melestarikan keberadaan mata air Tataneyan.

Tabel 8. Nilai Pemanfaatan Air untuk Pembibitan Ikan

\begin{tabular}{clccc}
\hline No & Jenis Ikan & $\begin{array}{c}\text { Harga Rata }- \\
\text { rata(Rp/Ekor) }\end{array}$ & $\begin{array}{c}\text { Volume rata-rata } \\
\text { (Ekor/Thn) }\end{array}$ & $\begin{array}{c}\text { Nilai Manfaat } \\
\text { (Rp/Thn) }\end{array}$ \\
\hline 1 & Nila & 500 & 40.000 & 20.000 .000 \\
2 & Mas & 1000 & 10.000 & 10.000 .000 \\
3 & Koi & 15.000 & 5000 & 75.000 .000 \\
\hline & Total & 16.500 & 55.000 & $\mathbf{1 0 5 . 0 0 0 . 0 0 0}$ \\
\hline
\end{tabular}

Sumber : Data Olahan dari kuesioner

Tabel 9. Nilai/Manfaat Ekonomi Air di Kawasan Mata Air Tataneyan

\begin{tabular}{|c|c|c|c|}
\hline No & Jenis Pemanfaatan & $\begin{array}{c}\text { Nilai /Manfaat } \\
\text { (Rata-rata per tahun) } \\
(\mathbf{R p})\end{array}$ & $\begin{array}{c}\text { Persentase } \\
(\%)\end{array}$ \\
\hline \multirow[t]{3}{*}{1} & Manfaat Langsung & & \\
\hline & -Domestik Rumah Tangga & 791.424 .000 & 49,88 \\
\hline & -Permandian Umum & 630.291 .372 & 39,72 \\
\hline \multirow[t]{4}{*}{2} & Manfaat Keberadaan & & \\
\hline & - pembibitan ikan & 105.000 .000 & 6,62 \\
\hline & - Irigasi Pertanian Kangkung & 60.000 .000 & 3,78 \\
\hline & Jumlah & 1.586 .715 .372 & 100 \\
\hline
\end{tabular}

Sumber : Data Olahan 


\section{KESIMPULAN DAN SARAN}

\section{Kesimpulan}

Valuasi sumberdaya air kawasan mata air Tataneyan di Kelurahan Kinilow I, Kecamatan Tomohon Utara, Kota Tomohon adalah sebesar Rp.1.586.715.372/ tahun. Nilai manfaat langsung untuk kebutuhan domestik rumah tangga memberikan kontribusi yang paling tinggi yaitu Rp. 791.424.000/tahun, kemudian nilai manfaat langsung untuk permandian umum yaitu Rp. 630.291.372/tahun, dan nilai manfaat keberadaan untuk pembibitan ikan sebesar Rp. 105.000.000/tahun. Sedangkan yang paling rendah nilai manfaat keberadaan untuk irigasi pertanian kangkung sebesar Rp. 60.000.000/tahun.

Berdasarkan hasil perhitungan diperoleh surplus konsumen yang lebih besar dari nilai rata rata willingness to pay (EWTP) yaitu sebesar Rp.144.145,98. Ini berarti keseluruhan konsumen menerima keuntungan lebih dari harga sebenarnya yang mampu mereka bayar dalam memanfaatkan mata Air Tataneyan.

\section{Saran}

Perlu adanya koordinasi antara masyarakat dan pemerintah setempat dalam hal kebijakan pengelolaan dan pemanfaatan sumber daya air di kawasan mata air Tataneyan.

Masyarakat sekitar kawasan mata air Tataneyan harus bekerjasama untuk menjaga kebersihan mata air Tataneyan juga dapat memanfaatkan sumber daya air secara lebih optimal dalam rangka menjaga kelestarian mata air tersebut.

\section{DAFTAR PUSTAKA}

Anggraeni, Septia. 2011. Nilai Ekonomi Air Untuk Rumah Tangga dan Keramba Di Seksi Pengelolaan Taman Nasional(sptn) Wilayah ii Semitau Taman Nasional Danau Sentarum (tnds) Kabupaten Kapuas Hulu. (Jurnal). Fakultas kehutanan, Universitas Tanjungpura.

Badan UNESCO Tahun 2002
Dahlan, E. 2014. Pemanfaatan Sumber Daya Air Di SUB DAS Lubuk Paraku Sumatera Barat. (Jurnal). Fakultas Kehutanan IPB

Eriyati. 2010. Analisis Valuasi Ekonomi Lingkungan Kesediaan Membayar Masyarakat Sekitar Sungai Siak. (Jurnal Ekonomi). Fakultas Ekonomi. Universitas Riau Kampus Panam.

Gleick, P.H. 2000. The World's Water. The Biennial Report on Fresh water Resources: 2000-2001. Island Press, Washington, D.C.

Harmayani, Diana. dan Konsukartha. 2007. Pencemaran Air Tanah Akibat Pembuangan Limbah Domestik Di Lingkungan Kumuh Studi Kasus : Banjar Ubung Sari, Kelurahan Ubung. (Jurnal). Jurusan Teknik Sipil. Fakultas Teknik Universitas Udayana.

Harnanto, Aris. 2007. Pengelolaan Sumber Daya Air Konsep Dan penerapannya. Bayumedia Publishing. Malang.

Isnin, M. dan Basri. H. 2012. Nilai Ekonomi Ketersediaan Hasil Air Dari Sub Daerah Aliran Sungai (DAS) Krueng Jreu Kabupaten Aceh Besar. (Jurnal).Fakultas Pertanian Unsyiah Banda Aceh Darussalam.

Jusuf, G. 2015. Blue Gold. PT BERITA NUSANTARA. Jakarta

Kalitouw, W. D. 2015. Valuasi Ekonomi Hutan Mangrove Di Desa Tiwoho Kecamatan Wori Kabupaten Minahasa Utara. (Jurnal). Jurusan Sosial Ekonomi, Fakultas Pertanian Unsrat.Manado.

Kodoatie, J. dan Sjariet, Roestam. 2010. Tata Ruang Air : C.V ANDI OFFSET. Yogyakarta.

Munaza, Rizki. 2015. Analisis Nilai Sosial Ekonomi Konservasi Satwa Liar pada Ruang Terbuka Hijau di Kota Medan. (Skripsi). Fakultas Kehutanan. Universitas Sumatera Utara. 
Nasution, M. S., Purwoko. A., \& Hartini K.S. 2015. Analisis Willingness to Pay Masyarakat terhadap Mata Air Aek Arnga di Desa Sibanggor Tonga, Kecamatan Puncak Sorik Marapi, Kabupaten Mandailing Natal. (Jurnal). Fakultas Pertanian. Universitas Sumatera Utara.

Pearce, D. W and Moran. D. 1994. The economic value of Biodiversity earthscan. London

Peraturan Menteri Dalam Negeri Nomor 23 Tahun 2006 tentang Pedoman Teknis dan Tata Cara Pengaturan Tarif Air Minum pada perusahaan Daerah Air Minum pada perusahaan Daerah Air Minum.

Peraturan Pemerintah Pasal 8 Nomor 82 tahun 2001 tentang Pengelolaan Kualitas air dan Pengendalian Pencemaran Air.

Peraturan Pemerintah Republik Indonesia Nomor 16 Tahun 2005 Tentang Pengembangan Sistem Penyedia Air Minum.

Putri P. R. D. 2013. Nilai Ekonomi Air Daerah Aliran Sungai (DAS) Way Orok Sub DAS Way Ratai Desa Pesawaran Indah Kecamatan Padang Cermin Kabupaten Pesawaran Provinsi Lampung. (Skripsi). Jurusan Kehutanan. Fakultas Pertanian. Universitas Lampung.

Saparuddin. 2010. Pemanfaatan Air Tanah Dangkal Sebagai Sumber Air Bersih Di Kampus Bumi Bahari Palu. (Jurnal). Palu : Jurusan Teknik Sipil. Fakultas Teknik Universitas Tadulako.
Sarrah, S., U. Syukur \& Alam A. S. 2015. Nilai Ekonomi Manfaat Hidrologis Hutan Di SUB DAS Sombe Untuk Kebutuhan Konsumsi Air Rumah Tangga Di Kelurahan Palupi Kecamatan Tatanga Kota Palu. (Jurnal). Fakultas Kehutanan. Universitas Tadulako Palu.

Sudita, M dan Antara, M. 2006. Nilai Sosial Ekonomi Air Kawasan Pura Tirta Empul Desa Manukaya, Kabupaten Gianyar Bali, suatu pendekatan ekonomi. (Jurnal). Jurusan Sosek. Fakultas Pertanian Unud Bali.

Sumaryanto dan Sinaga, M. 2003. Estimasi Nilai Ekonomi Air Irigasi Dan Strategi

Pemanfaatannya Dalam Penentuan Iuran Irigasi. (Jurnal). Pusat Penelitian Sosek Badan Litbang Pertanian \& Institut Pertanian Bogor.

Suparmoko, M., Sudirman, D., Setyarko, Y \& Wibowo, H. S. 2014. Valuasi Ekonomi Sumberdaya Alam \& Lingkungan. BPFE. Yogyakarta.

Undang Undang Republik Indonesia Nomor. 7 Tahun 2004. tentang Sumber Daya Air.

Widada. dan Darusman, D. 2004. Nilai Ekonomi Air Domestik Dan Irigasi Pertanian : Studi Kasus Di Desa-Desa Sekitar Kawasan Taman Nasional Gunung Halimun. (Jurnal). Fakultas Kehutanan. Institut Pertanian Bogor. 